\title{
MINISTERIO DE LOS PRESBÍTEROS Y MINISTERIO DE LOS LAICOS
}

Autor: Mons. Joseph. Doré. Arzobispo de Strasbourg.

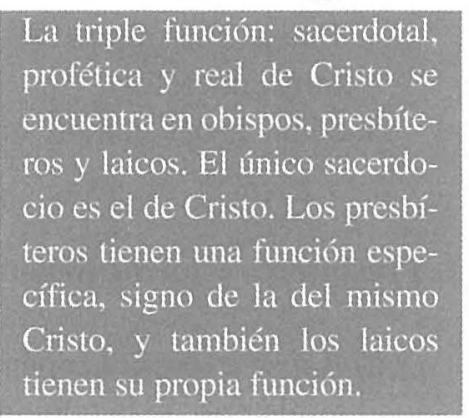

DOI: https://doi.org/10.52039/seminarios.v49i168.827

Preguntarnos por la relación entre ministerio de los presbíteros y ministerios laicos ${ }^{1}$, no es plantear una pregunta que concierne solamente a la organización de la Iglesia, el estado de vida y las condiciones de existencia de sus miembros, la psicología y la historia de las mentalidades cristianas -aun siendo todo esto muy importante-. Es en primer término y ante todo provocar la pregunta sobre el sentido de la

* Traducción de Alonso Morata revisada por Jacqueline Limes, del artículo aparecido en Esprit et Vie, 80 (03) pp. 3-7.

${ }^{1}$ Sucede que las misiones eclesiales ahora confiadas a laicos llevan a algunos a temer que resulte de ello un más o menos extenso desconocimiento e incluso una devaluación de los ministerios ordenados. A continuación encontraremos una intervención sobre el tema de la relación entre ministerio de presbíteros y ministerios laicales, que tuvo lugar en el marco de una sesión organizada los días 14 y 15 de octubre de 2002 por el Servicio diocesano de Formación permanente del clero de la diócesis de Strasbourg. 
ordenación sacramental. Es por lo tanto plantear un problema de fe, y que por supuesto no es ajeno a la pastoral en cuanto que la entiende como el verdadero servicio eclesial de la fe.

En el planteamiento que voy a hacer aquí de este problema voy a presentar cinco puntos que, subrayando lo que se refiere a la fe y a la pastoral, lo haga a la vez desde la teología:

1. Presbíteros y laicos tienen prerrogativas y tareas comunes.

2. Unos y otros tienen su relación con Cristo y están unidos en la Iglesia.

3. Los presbíteros tienen una función peculiar en el pueblo cristiano.

4. Existe una ministerialidad laica, pero ésta presenta caracteres muy concretos.

5. Se ha de dar siempre una colaboración entre presbíteros y laicos.

\section{Presbíteros y laicos tienen tareas y prerrogativas comunes}

a) Así se expresa Lumen gentium, $n^{\circ}$ 20: «Los obispos han recibido el ministerio de la comunidad para ejercerlo junto con los presbíteros y los diáconos. Ellos presiden en el nombre y lugar de Dios, la grey de la que son pastores como maestros de doctrina, por el sacerdocio del culto sagrado y por el ministerio del gobierno.»

Es, por tanto, en el ejercicio del ministerio de «presidencia» como los obispos están al servicio de la comunidad, según la triple función profética (la doctrina), sacerdotal (la celebración), real (el «gobierno»). En cuanto a los sacerdotes «colaboradores privilegiados del orden episcopal» son consagrados para «predicar el Evangelio, para ser los pastores de los fieles y para celebrar el culto divino como verdaderos sacerdotes del Nuevo Testamento» (Lumen gentium, 28).

Pero también Lumen gentium 34-36, dice que los fieles han sido a su vez «incorporados a Cristo por el bautismo, son constituidos Pueblo de Dios, participando a su manera en la función sacerdotal, profética y real de Cristo».

b) La triple función se encuentra pues simultáneamente en los obispos, presbíteros y laicos. Se deducen de aquí muchos puntos claros: 
- No se puede saber lo que es propio de los presbíteros sin aclarar el rol de los laicos, ya que tanto unos como otros tienen las mismas características fundamentales. Oponerlos, separarlos sería desconocer a unos y a otros.

- En tanto que pertenecen a la Iglesia, los unos y los otros, presbíteros y laicos se encuentran y se distinguen dentro de la Iglesia. No se puede decir, por ejemplo, que las tareas internas estarían reservadas a los primeros, mientras que lo propio del compromiso de los segundos sea solamente la orientación ad extra.

- Inversamente sin embargo, todo eso, incluida por consiguiente la misión de los sacerdotes, ocurre realmente en el mundo.

- En cualquier hipótesis, presbíteros y laicos sólo pueden definirse como tales en relación con Cristo y en dependencia directa con él, porque él es la única fuente, en cristianismo, de todo profetismo, de todo sacerdocio, de toda realeza. Aquí como en otras partes, es pues de él de quien se trata de «volver a partir».

\section{Cristo y la Iglesia}

a) Es preciso en primer lugar ver lo que significa esta triple función desde Cristo, tanto más cuanto que es ejerciéndola como él mismo se manifiesta como el Cristo (Ungido) de Dios.

- La dimensión profética comprende su papel de Revelador. Da testimonio de la verdad; es el profeta por excelencia. ¿Pero por qué lo es y puede serlo? Porque él es la encarnación del hombre del que, en Dios, es la perfecta imagen del Padre. Él es el Hijo engendrado por el Padre para ser su palabra, y es porque se encarna como tal por lo que revela al Padre. Su función de revelador del Padre está arraigada en su mismo ser.

Cristo no es revelador de Dios sino para abrir el acceso directo a aquellos que escuchen su voz y sigan su camino: así desempeña la función de sacerdote. Ver la carta a los Hebreos: él es «el siempre vivo dispuesto a interceder en nuestro favor», es decir ejerciendo su mediación, y de este modo «asegurar»nuestra relación con Dios. «Él es ahora la salvación para todos los que escuchan su voz», dice uno de nuestros prefacios. También el único sacerdocio es, a decir verdad, el de Cristo, 
que no cesa de actualizarlo para nosotros en la gloria de Dios a donde él ha llegado.

- Reuniendo así, alrededor de su palabra de profeta, un pueblo de creyentes a los que él, como sacerdote, da acceso a la realidad viviente de Dios, Cristo desempeña a la vez, una función real, en la cual desembocan las dos anteriores. También ella encuentra su posibilidad solamente en el ser mismo de Cristo. Segundo y último Adán, primer nacido de toda creatura y de entre los muertos, puede atraer al reino del Padre, a los creyentes y celebrantes de su Misterio. Él los constituye en un pueblo que unifica su espíritu.

Se debe decir a la vez que Cristo ejerce una única y sola función una vez por todas en el «tiempo señalado», la triple función -profética, sacerdotal y real- que justamente le revela como el Cristo, y que él no cesa de ejercer por nosotros día tras día. Es necesario también añadir: la Iglesia es precisamente lo que resulta, en la humanidad y en el mundo, de la realización efectiva de esta triple función. A quienes ésta alcanza, esta última permite, en efecto, tomar parte a su vez, y cada uno según su condición, en su ejercicio: su logro mismo será que todos los que se beneficien de ello podrán llegar a ser profetas, celebrantes y reyes. Y de ahí resultará que puedan ser designados con justicia «cristianos» es decir como los que verdaderamente son de «Cristo» y como los que forman unidos el «Cuerpo de Cristo».

Conclusión: todos los cristianos participan de la triple función cristológica/ crística. O sea: todos han accedido ante Dios tres veces santo: todos reciben la posibilidad y la misión de dar testimonio de él; todos están en disposición de ejercer la realidad del servicio de salvación del mundo.¿Qué lugar ocupará en esta dinámica el presbítero?

\section{Los sacerdotes desempeñan en el pueblo cristiano una función específica}

a) La salvación en «visibilidad histórica»

De hecho por la mediación histórica, encarnada, de su propio Hijo en Jesús es como Dios ha llevado a cabo su obra de salvación en la humanidad. Dicho de otro modo, ha realizado la salvación «median- 
te su visibilidad histórica mundana»: en Jesucristo la salvación ha llegado a la humanidad de manera visible e histórica en este mundo: «Felipe, quien me ve, ve a Padre».

Ahora bien, es necesario plantearnos bien la pregunta: ¿de qué manera sigue llegando ahora la salvación a nosotros? Por el Espíritu Santo, por supuesto... pero ¿en sí significa siempre que lo hace de manera histórica o no? En otras palabras, ¿la salvación promovida únicamente por Jesucristo nos llega ahora sola y directamente por el Espíritu, o bien la hace llegar también y siempre por medio de una «visualización histórica», como fue el caso por y en Jesús?

Si se le pudiera captar siempre según un modo histórico y visible, no podría en adelante tratarse de la visibilidad de Jesucristo mismo con seguridad, porque él resucitó y «subió a los cielos», volvió junto a su Padre. Es necesario, pues, que aparezca otra clase de visibilidad además de la suya propia: una visibilidad histórica que por cierto no se sustituiría por la suya, sino que podría prolongarla representándola, mediatizarla siendo signo de ella...

b) La economía sacramental y los sacerdotes

Precisamente esta es la característica del sacramento: Tal es la economía sacramental, en función de la cual la Iglesia adquiere su sentido, y el sacerdote encuentra su lugar. En la Iglesia (toda ella sacramental), habrá hombres que serán elegidos y enviados para poner en este mundo, hoy, los signos visibles, eficaces, históricos, y por tanto propiamente sacramentales, del don que Dios ofrece al mundo una vez por todas en Cristo, y que puede continuamente comunicar por medio de su Espíritu a todos aquellos que se muestran acogedores. Estos hombres serán los sacerdotes.

No hay otra justificación fundamental del sacerdocio ministerial. Por medio de los sacerdotes así concebidos, Dios continúa, a través del tiempo y los diversos lugares, proponiendo y dando su salvación según las leyes mismas según las cuales la ha entregado de una vez para siempre en Jesucristo, o sea mediante gestos y palabras de hombre, por una mediación y presencia de hombre.

Así la salvación no deja de señalarse y significarse en el mundo a la vez como iniciativa totalmente gratuita de Dios y como propuesta hecha «muy cerca de nosotros», o sea con visibilidad histórica, por 
mediación humana simbólica e histórica, significante y sacramental. No sustituyéndose el ministerio de Cristo, sino en la dinámica de su Espíritu, y sin otra intención que la de continuar significando la iniciativa de Dios.

Hay hombre elegidos y llamados, ordenados y enviados precisamente para hacer significativa ante sus hermanos en humanidad que la salvación de Dios, a la vez, encuentra su única fuente en la iniciativa divina totalmente gratuita, y sin embargo no cesa de proponerse a ellos en total proximidad humana.

Según Mt 9, 1-7, habiendo visto a Jesús que perdona sus pecados al paralítico que ha curado antes, «la multitud glorifica a Dios por haber dado tal poder a los hombres». «A los hombres»: en lugar del singular que se esperaría aquí porque Jesús es único en esta causa, se utiliza de hecho un plural. De la acción de Jesús la narración evangélica no disocia la misión de aquellos que se han convertido en sus testigos, sus «apoderados», sus ministros, en las comunidades postpascuales en el seno de las cuales se está fraguando poner por escrito las tradiciones evangélicas.

\section{c) En y por el pueblo cristiano}

Todo este ministerio de presbíteros no existe, sin embargo, más que en y por el pueblo cristiano en este mundo. Así pues, ¿cuál es su fruto real, cuál la señal de su fecundidad propiamente ministerial? Por el ejercicio de la función de los sacerdotes con respecto a los fieles, se produce para el pueblo cristiano algo análogo a lo que se ha dicho poco antes a propósito de los efectos del ejercicio por el mismo Cristo de su triple función: resulta de ello una asociación de los fieles a la triple función del sacerdote.

- Función sacerdotal: los sacerdotes son los únicos que pueden presidir la eucaristía, actuando únicamente in persona Christi. Pero lo realizan para permitir a todos los cristianos dar su propio culto a Dios vivo y verdadero, el culto real y sacerdotal de los bautizados. De manera que cada fiel que participa en las celebraciones que presiden los pastores tiene, él mismo, acceso a Dios vivo y verdadero.

- Función profética: todo el sentido de este aspecto del ministerio de los presbíteros es el de formar creyentes aptos para testimoniar a su alrededor la palabra que ellos hubieran recibido. Siempre que 
estos últimos asuman de hecho su testimonio, no entrarán en competencia con la misión profética de los presbíteros: con total seguridad, no harán otra cosa que mostrar los frutos de su ejercicio.

- Función real: la participación de los fieles en la animación y en la vida del pueblo cristiano y al servicio de la caridad es el mejor signo de la fecundidad de ministerio «real» de «gobierno» de los sacerdotes para el crecimiento de la Iglesia de Cristo. Del simple hecho de que él vive y practica su fe, todo cristiano aporta su piedra a la vida de la Iglesia misma. Y contribuye por su parte al servicio y al testimonio que está llamado a dar en el mundo.

\section{Existe una ministerialidad laica, pero presenta caracteres muy concretos}

a) Se acaba de decir: todo cristiano, por el solo hecho de que es participante en el Misterio de Cristo por su bautismo, es desde ese momento llamado y apto para participar, en la Iglesia, de la misión profética, sacerdotal y real de Cristo a la que le remite su mismo nombre de «cristiano». Dicho de otro modo, todo bautizado forma parte de la «nación santa», del «pueblo elegido», del «sacerdocio real».

El simple hecho de «practicar su religión»como se suele decir, o de «confesar su fe» y vivirla, contribuye por su parte, a «hacer que exista la Iglesia» en el mundo y para él. Pero se puede ir todavía más lejos en el compromiso en el seno de la Iglesia en este mundo: son innumerables, los servicios que los fieles pueden llevar a cabo, ya sea por la conservación y la decoración de las iglesias, por la animación litúrgica y la propuesta de la fe, o por la preparación a los sacramentos y la acción caritativa. Para llevar a cabo tales servicios, no tienen necesidad de ninguna otra misión especial: el bautismo es suficiente, con la generosidad y el compromiso de la fe, a los que él llama desde sí mismo.

b) Pero se puede también, deseándolo todo y pudiendo, permanecer siendo completamente laico, recibir y por lo tanto tener un lugar más importante, y más cualificado todavía, en la vida de la Iglesia, hasta el punto de que será posible de hecho el estado de «ministerios laicales». Importa sin embargo ver con precisión de qué se habla en cada caso. 
Se dirá que pueden ser considerados como «ministros laicos», los cristianos que, participan de toda manera ellos también en la triple función de Cristo sobre la única base del bautismo y de la confirmación, lo harán además presentando caracteres concretos, y por consiguiente con un título muy particular. Ellos cumplen tareas bien precisas. Estas tareas:

- Tienen que estar correspondiendo a una prestación de importancia vital para la Iglesia, y ejerciéndose necesariamente en el ámbito de una o más de las tres misiones o funciones crísticas muchas veces evocadas aquí;

- otorgando una verdadera responsabilidad, a ejercer con cierta duración;

- oficialmente confiadas, no solamente al seguimiento de una llamada, de un discernimiento y de una formación, sino también por una misión expresamente recibida del obispo, y de una comunión efectivamente verificada y mantenida con él.

\section{Debe darse incesantemente una colaboración entre presbíteros y laicos}

- No podemos sino considerar como una suerte o una gracia para la Iglesia el hecho de que no exista solamente por el ministerio de sus sacerdotes, sino igualmente por el servicio cumplido y el compromiso consentido por un número creciente de fieles cristianos expresamente llamados, formados y enviados.

- Tenemos necesidad, en primer lugar, de esforzarnos por ser claros en este tema. Quien no está ordenado ciertamente no debe actuar como si lo estuviera; pero, de forma correlativa, quien ha recibido una misión debe tener oportunidad de ejercerla, incluso si esa no es la propia de un sacerdote, sin verse a priori acusado de «deseo de poder» o de clericalismo, porque se esfuerza en ponerla en práctica,

- Evidentemente. Estamos allá en una situación bastante nueva con relación a un estado de Iglesia en la que prácticamente toda su vida era, no solamente, conducida sino totalmente garantizada solamente por los presbíteros, los fieles no hacían más que beneficiarse de algunos servicios eclesiales, y no aportando de hecho más que un poco de 
concurso activo a su realización. No hay desde entonces por qué asombrarse de que la «nueva situación» suponga aquí o allí algunas fricciones y llame, pues, de una y otra parte a reajustes. La experiencia prueba ampliamente que allí donde tienen lugar los diálogos y debates deseables entre las partes interesadas, resulta muy posible llegar a felices y fecundas colaboraciones.

- Todo esto nos invita, a nosotros sacerdotes, a privilegiar cierto número de esperanzas. Entre otras las siguientes: al mismo tiempo que una llamada y un discernimiento cuidadoso, el acompañamiento atento, la puesta en unión constante de unos con los otros, el cuidado incesante de la colaboración, el servicio permanente de la comunión.

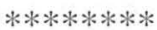

Sin duda no sabría concluir estas reflexiones sobre los ministerios de otra manera que recordando la colecta de la misa votiva del Misal romano «por los sacerdotes»: «Tu quieres, Señor, que tu pueblo entero participe en el sacerdocio de tu Hijo, y tú confías a algunos miembros el encargo de santificarlos, de guiarlos y de enseñarles en el nombre de Cristo, concede a aquellos que tú has hecho tus sacerdotes la gracia de ser fieles a su misión: que por su ministerio y toda su vida ayuden a los hombres y sirvan a tu gloria. Por Jesucristo, nuestro Señor».

Pero esta plegaria sugestiva debería encontrar útilmente una prolongación operativa en esta clara invitación de la exhortación apostólica postsinodal Christi fideles laici ( $\left.\mathrm{n}^{\circ} 23\right)$ : «Los pastores, en consecuencia, deben reconocer y promover los ministerios, los oficios y las funciones de los fieles laicos, oficios y funciones que tienen su fundamento sacramental en el bautismo, en la confirmación, y además, para muchos de ellos, en el matrimonio». 


\section{Entrevista a Mons. Joseph Doré, Arzobispo de Strasbourg}

Pregunta: ¿Cuántos y cuáles son los ministros laicos en su diócesis?

Mons. Doré: Son, salvo si el trabajo de definición de la misión no se ha hecho bien, aquellos que nosotros llamamos en la Alsacia los «cooperadores pastorales». No actúan estos solamente a título de su bautismo sino a título de la misión recibida. Algunas veces existe una fluctuación del lenguaje, pero no se puede llamar «ministerio» a todo servicio confiado y desempeñado en la Iglesia.

Pregunta: Cuando se proyectan Equipos de animación pastoral (EAP) ¿cuál es el estatuto de las personas laicas componentes de los mismos?

Mons. Doré: Se trata de personas que, hablando con precisión, no desempeñan un cargo pastoral sino que «participan en su ejercicio», bajo una u otra forma. Pero no puede ser reconocido ministro laico sino aquel que desempeña, por su parte, una tarea no solamente determinada, sino que reúne de hecho los tres criterios que acabo de señalar.

Pregunta: ¿Quién puede enviar a una misión? ¿Por ejemplo para ser ministro de la comunión?

Mons. Doré: Cuando se trata de un ministerio, es el obispo el que encarga la misión. Por el contrario, cuando la actividad en marcha parece ser del orden de un servicio y no de un ministerio, y por lo tanto dimanar de la responsabilidad bautismal como tal -llevar la comunión por ejemplo-, quien ejerce en el lugar la carga pastoral es entonces cualificado por la llamada y el envío. 